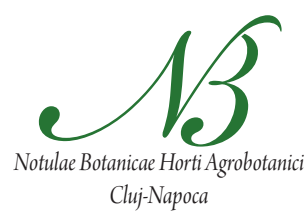

\title{
Genetic Stability of In vitro Multiplied Phalaenopsis gigantea Protocorm-like Bodies as Affected by Chitosan
}

\author{
Samira SAMARFARD ${ }^{1}$, Mihdzar A. KADIR ${ }^{1 *}$, Saleh B. KADZIMIN², \\ Seyedali RAVANFAR ${ }^{1}$, Halimi M. SAUD ${ }^{1}$ \\ ${ }^{1}$ Universiti Putra Malaysia, Faculty of Agriculture, Department of Agriculture Technology, 43400, \\ Serdang, Selangor, Malaysia; Mihdzar@agri.upm.edu.my (*corresponding author) \\ ${ }^{2}$ Universiti Putra Malaysia, Faculty of Agriculture, Department of Crop Science, 43400, Serdang, Selangor, Malaysia
}

\begin{abstract}
Chitosan is a carbohydrate polymer derivative of chitin which presents in shell of crustaceans. This biopolymer is a non toxic and environmentally friendly, considered as a plant growth stimulator in some plant species. The present study investigates the effects of chitosan and media types on multiplication and genetic stability of Phalaenopsis gigantea protocorm-like bodies (PLBs). PLBs were inoculated in liquid New Dogashima Medium (NDM) and Vacin and Went (VW) supplemented with various concentrations of chitosan $(0,5,10,15,20$ and $25 \mathrm{mg} / \mathrm{L})$. The highest PLB multiplication was observed on VW and NDM supplemented with $10 \mathrm{mg} / \mathrm{L}$ chitosan with mean number of PLBs 177 and 147, respectively. Chitosan promoted the formation of juvenile leaves and the highest number was observed in NDM supplemented with $20 \mathrm{mg} / \mathrm{L}$ chitosan with mean number of 66 leaves after 8 weeks of culture. Genetic stability was assessed among mother plant and secondary PLBs after 2, 4, 6, and 8 weeks of culture in liquid media. 8 out of 10 ISSR markers produced a total of 275 clear and reproducible bands with mean of 6.9 bands per primer. The secondary PLBs produced during sub-culturing process of chitosan treated liquid culture were genetically uniform and similar to mother plant.
\end{abstract}

Keywords: Chitin, Chitosan, ISSR, New Dogashima Medium, Phalaenopsis gigantea, PLBs

\section{Introduction}

The Orchidaceae family is considered as one of the most diverse flowering plant families, comprising of 25,000 species and more than 800 identified genera. Orchids contribute around $8 \%$ of global floriculture trade (Chugh et al., 2009). Phalaenopsis gigantea is one species found in the lowland forests of the state of Sabah, Malaysia. Deforestation and over-collections have resulted in near extinction of this species (Rodrigues and Kumar, 2009). This tropical orchid is commonly known as Elephant's Ear orchid with its enormous leaves. Phalaenopsis gigantea has the potential of producing beautiful hybrids. This species is usually propagated through the formation of new buds induced at the bases of mature plants. But the number of new buds initiated by a mature plant is very low (Shu-guo, 2008). The induction of protocorm-like bodies (PLBs) or callus from the protocorm using liquid media and shake cultures has become a reliable method for mass propagation due to the great number of PLBs that can be achieved with short labor time. The aeration system of liquid medium and the close contact of explants with medium may facilitate the uptake of oxygen, nutrients, phytohormones and consequently lead to increase the rate of plant regeneration (Sandal et al., 2001).

In attempts to accelerate PLBs and plantlet production, synthetic phytohormones, such as thidiazuron (TDZ), indole-3-butyric acid (IBA), 1-naphthalene ace- tic acid (NAA), and 6-benzyl amino purine (BAP), have been widely applied (Nayak et al., 1997; Roy and Banerjee, 2003; Saiprasad et al., 2004). However, applying synthetic hormones for increasing PLB multiplication leads to induce somaclonal variation (Araditti and Ernest, 1993). Molecular markers have been recently used as conventional tools for assessment of genetic stability of in vitro products. Inter-simple sequence repeat (ISSR) have also been used to assess genetic fidelity in several regenerated plants including banana (Lakshmanan et al., 2007), Camellia sinensis (Devarumath et al., 2002), and Swertia chirayita (Joshi and Dhawan, 2007).

Chitosan is a cationic polymer and $\mathrm{N}$-deacetylated product derivative of chitin which is present in shells of crustaceans and cell wall of fungi (Devlieghere et al., 2004). This component is an environmentally friendly carbohydrate polymer and has been reported to stimulate growth of some plant species, including orchids (Nge et al., 2006). It also has been reported that the supplementation of chitosan for in vitro regeneration of Dendrobium 'Eiskul' did not induce somaclonal variations (Pornpienpakdee et al., 2010). Phalaenopsis gigantea has produced outstanding novelty hybrids and has become a much sought after species that result in over-collection from its natural habitat leading to eventual extinction. This species is inherently difficult to propagate in the nature. This species is usually propagated through the formation of new buds at the bases of mature plants. However, this method 
178

of propagation is very inefficient as the number of new buds produced by a plant is very low. In the current study efforts to enhance PLB multiplication using different liquid media supplemented with chitosan and assessment of genetic stability across regenerated PLBs and mother plant were undertaken.

\section{Materials and methods}

\section{Plant materials and culture conditions}

Young leaves from in vitro donor plant (mother plant) were used for induction of initial PLBs. The leaf tip segments $(1.5 \mathrm{~cm}$ in length) were excised and cultured on semi solid New Dogashima medium (NDM) (Tokuhara and Mii 1993; 1998) supplemented with $0.1 \mathrm{mg} / \mathrm{L}$ thidiazuron (TDZ) and $1.0 \mathrm{mg} / \mathrm{L}$ naphthalene acetic acid (NAA). The protocol was selected based on an earlier report on Phalaenopsis gigantea (Niknejad et al., 2011). The cultures were placed under a 16 -h photoperiod at an irradiance of $30 \mu \mathrm{mol} \mathrm{m}{ }^{2} \mathrm{~s}^{1}$ and temperature of $25 \pm 2^{\circ} \mathrm{C}$. The earliest morphological sign of PLB formation appeared as swellings on the adaxial side of leaf segments within 4-6 weeks of culture; small round bodies (small initial PLBs) were transferred to hormone free NDM and used as plant material (Fig. 1a).

\section{Media and chitosan preparation}

The interaction of different media types and chitosan concentrations on PLB multiplication of P.gigantea was investigated. For this purpose, liquid VW (Vacin and Went, 1949) and New Dogashima medium (NDM) (Tokuhara and Mii 1993; 1998) were used and each liquid medium was supplemented with $20 \%$ coconut water and different concentrations of chitosan $(0,5,10,15,20$ and $25 \mathrm{mg} / \mathrm{L})$. Chitosan powder labeled as low molecular weight and $75 \%$ degree of deacetylation (Sigma Aldrich) was selected for the preparation of stock solution. One gram of chitosan powder was dissolved and stirred in 1\% acetic acid and heated to $35^{\circ} \mathrm{C}$, constantly agitating for 24 hours. The $\mathrm{pH}$ of chitosan stock was adjusted to 5.5 using $2 \mathrm{M} \mathrm{NaOH}$ and the solution was stirred for 4 hours. Ultimately, the $\mathrm{pH}$ of media was adjusted to 5.4 followed by autoclaving for $20 \mathrm{~min}$ at $121^{\circ} \mathrm{C}$ and $15 \mathrm{psi}$.

\section{Proliferation conditions}

For evaluating the multiplication of secondary PLB, five initial PLBs $(0.25-0.3 \mathrm{~g})$ induced from leaf segments of donor plant were cultured in $200 \mathrm{ml}$ Erlenmeyer flasks containing $100 \mathrm{ml}$ of growth media (VW and NDM). The PLBs produced in each flask were transferred to freshly prepared medium every 14 days for two months. The cultures were shaken at $60 \mathrm{rpm}$ on a rotary shaker under 16-h photoperiods using fluorescence lighting of $30 \mu \mathrm{mol} \mathrm{m} \mathrm{s}^{1}$ per day and the cultures were maintained at $25 \pm 2^{\circ} \mathrm{C}$. The number of PLBs and their fresh weights were determined at the end of the experiment.

\section{Experimental design and statistical analysis}

The study on in vitro multiplication of PLB was laid out in a factorial combination of treatments based on randomized complete block design (RCBD). The recorded data were analyzed using the analysis of variance (ANOVA) and means separated using Duncan's New Multiple Range Test (DNMRT). All statistical data were tested at the $5 \%$ level of significance for comparison between treatment means. In this study 5 experimental units were considered for each replicated and the experiment consisted of 3 replicates. The results are presented as means \pm the standard error.

\section{DNA extraction}

Leaves of in vitro mother plant were used to isolate genomic DNA for PCR amplification and termed as MP. To study the genetic stability among MP and regenerated PLBs after 2, 4, 6, and 8 weeks of culture, the secondary PLBs obtained at the end of every two weeks of sub-culturing (S1, S2, S3 and S4) were randomly used to isolate genomic DNA. Samples from MP, S1, S2, S3 and S4 were first washed with tap water and sterilized in $10 \%(\mathrm{v} / \mathrm{v})$ Clorox $^{\circ}$ solution for 5 minutes. The PLBs were rinsed three times with distilled water, wrapped with aluminum foil and stored at $-80^{\circ} \mathrm{C}$ for DNA extraction. Genomic DNA was extracted using cetyltrimethylammonium bromide (CTAB) method (Doyle and Doyle, 1990) with minor modification. Quality and quantity of DNA was monitored by spectrophotometry and gel inspection.

\section{PCR amplification and gel scoring}

Eight primers were selected from a total of 10 ISSR primers for assessment of genetic fidelity (Tab. 1). PCR amplification was carried out in a total volume of $25 \mu \mathrm{L}$ including DNA templates $(20,30,40$ and $50 \mathrm{ng} / \mu \mathrm{L})$ and ISSR primers $(1 \mu \mathrm{M}), 12.5 \mu \mathrm{L}$ DreamTaq ${ }^{\text {mim }}$ Green PCR Master Mix (Fermentas, Inc, Hanover, USA) and 10.4 $\mu \mathrm{L}$ nuclease free water. Amplification was performed in a programmable Thermal Controller (MJ Research Inc., USA) which was consisted of an initial denaturation step at $94^{\circ} \mathrm{C}$ for 5 minutes, followed by 35 cycles of $30 \mathrm{~s}$ denaturation at $94^{\circ} \mathrm{C}$, annealing temperature at $54.8-60.5^{\circ} \mathrm{C}$ for $90 \mathrm{~s}$ ( Tab. 1) and continued at $72^{\circ} \mathrm{C}$ for $90 \mathrm{~s}$ with a final extension at $72^{\circ} \mathrm{C}$ for 5 minutes. Amplified products were separated on $1.5 \%(\mathrm{w} / \mathrm{v})$ agarose gels. The molecular size of amplified PCR products were estimated using $1 \mathrm{~kb}$ DNA ladder (Fermentas, Inc, Hanover, USA). The digital image files were analyzed using UVIDoc software v.99.01 and fragment sizes were estimated based on DNA ladder. All the reactions were repeated three times. Only well-separated bands with high intensity were scored as present or absent for ISSR markers. The scoring of bands was done as 1 for presence and 0 for the absence of DNA bands in the gel. Electrophoretic DNA bands of low visual intensity that could not be readily differentiated as present or absent were considered ambiguous markers and were not scored. 


\section{Results}

Effects of different chitosan concentrations and media types on PLBs proliferation

Initial response of primary PLBs to different chitosan concentrations and media types was observed 2 weeks after culturing and it was consisted of protocorms swellings (Fig. 1b). The nodular structure from the swelling regions was observed after 3-4 weeks of cultivation (Fig. 1c), and these nodular tissues ultimately developed further and formed more secondary PLBs. The results exhibited significant differences $(p \leq 0.05)$ in PLB multiplication efficiency among different treatments (Fig. 2a). All treatments including the control were able to induce secondary PLBs with mean number of PLBs varying from 31 to 177 after 8 weeks of culturing. Regardless of media used, the best response was recorded at concentrations ranging from 5 to $15 \mathrm{mg} / \mathrm{L}$ of chitosan supplementation in both media and most PLBs were between 4-5 mm in diameter. Further increasing the amount of chitosan did not significantly improve the formation of secondary PLBs at $20 \mathrm{mg} / \mathrm{L}$. Chitosan at a concentration of $10 \mathrm{mg} / \mathrm{L}$ produced the highest mean number of PLBs in VW (177) and NDM (147), showing no remarkable difference in terms of PLB mean number (Fig. 1d). Conversely, NDM at 0, 20 and $25 \mathrm{mg} / \mathrm{L}$ chitosan induced the lowest mean number of secondary PLBs compared to the other treatments, since only 40-32 PLBs per flask were observed after 8 weeks of cultivation. VW at $25 \mathrm{mg} / \mathrm{L}$ chitosan did not show further prolifera- tion compared to the control. It was also observed that the effect of NDM at $15 \mathrm{mg} / \mathrm{L}$ chitosan on PLB proliferation was not statistically different $(p \leq 0.05)$ with VW at 20 mg/L chitosan (Fig. 2a).

\section{Effects of chitosan on leaf organogenesis}

The earliest morphological changes and differentiation of PLBs occurred after 5 weeks of culturing. Some tiny secondary PLBs were converted to mature PLBs during the first five weeks of culturing and ultimately the small emerging leaves appeared on the apical region of differentiated PLBs after 7-8 weeks of cultivation (Fig. 1e). The highest differentiation potential of PLB and leaf formation were observed in liquid NDM at a chitosan concentration of $20 \mathrm{mg} / \mathrm{L}$ with a significantly larger mean number of developing leaves (66) compared to the other treatments during the same period of culture. Interestingly, there was no significant difference $(p \leq 0.05)$ in mean number of leaves produced by NDM at $15 \mathrm{mg} / \mathrm{L}$ chitosan (42) and VW at $10 \mathrm{mg} / \mathrm{L}$ of supplemental chitosan (32). The highest number of new leaves in liquid VW treatments was observed at $10 \mathrm{mg} / \mathrm{L}$ chitosan supplementation (Tab. 2). Subsequently, the result showed that in the presence of chitosan in liquid culture, the success of leaf formation largely depended on the type of growth medium. The results showed that the interaction of NDM and chitosan was more effective on differentiation and conversion of mature PLBs to leaves when compared with the interaction of VW and chitosan.

Tab. 1. List of 10 ISSR primers used for PCR amplification and assessment of genetic stability across mother and secondary PLBs obtained during Sub-culturing process

\begin{tabular}{ccccc}
\hline Primer & Sequence $\left(5^{\prime}-3^{\prime}\right)$ & Tm & No. of bands & $\begin{array}{c}\text { Size range } \\
(\text { bp })\end{array}$ \\
\hline T06 & AGAGAGAGAGAGAGAGT & 56.9 & 6 & $400-1171$ \\
T05 & CGTTGTGTGTGTGTGTGT & 60.2 & 11 & $228-1537$ \\
UBC842 & GAGAGAGAGAGAGAGAC/TGGGGG & 60.2 & 6 & $935-3355$ \\
\hline I2 & ACACACACACACACACAT & 54.8 & 7 & $382-1851$ \\
UBC812 & GAGAGAGAGAGAGAGAA & 54.8 & 5 & $384-2329$ \\
I65 & AGAGAGAGAGAGAGAGCC & 61.8 & 8 & $484-3074$ \\
UBC834 & AGAGAGAGAGAGAGAGCT & 59.1 & 7 & $420-2655$ \\
I74 & ACTGACTGACTGACTG & 54.2 & 5 & $297-2028$ \\
I25 & ACACACACACACACACCA & 57.6 & - & - \\
\hline C09 & CAGATGGGAGTCAAGTCAAC & 60.4 & - & - \\
\hline
\end{tabular}

Tab. 2. Mean number of juvenile leaves after eight weeks of cultivation

\begin{tabular}{ccc}
\hline Chitosan $(\mathrm{mg} / \mathrm{L})$ & Mean number of juvenile leaves (NDM) & Mean number of juvenile leaves (VW) \\
\hline 0 & $5 \pm 0.9 \mathrm{e}$ & $8 \pm 0.8 \mathrm{e}$ \\
5 & $13 \pm 1.9 \mathrm{de}$ & $24 \pm 2.3 \mathrm{~cd}$ \\
10 & $17 \pm 2.03 \mathrm{de}$ & $32 \pm 1 \mathrm{bc}$ \\
15 & $42 \pm 3.07 \mathrm{~b}$ & $18 \pm 2.9 \mathrm{de}$ \\
20 & $66 \pm 13.5 \mathrm{a}$ & $13 \pm 1.7 \mathrm{de}$ \\
25 & $8 \pm 1.53 \mathrm{e}$ & $4 \pm 1.3 \mathrm{e}$ \\
\hline
\end{tabular}

According to analysis of variance (ANOVA), Values are exhibited as means \pm standard errors (SE); different letters within a column represent significant differences at $(p<0.05)$ 
180

Effects of different chitosan concentrations on PLB growth

Varying the concentrations of chitosan in VW and NDM led to differences in total fresh weight. The increase in total fresh weight of PLBs and initiated leaves was registered after eight weeks of culture. The results showed that treatment with $10 \mathrm{mg} / \mathrm{L}$ chitosan induced the highest mean total fresh weight in VW $(8.4 \mathrm{~g})$ and NDM $(7.3 \mathrm{~g})$ compared to other treatments. After eight weeks of culture, liquid VW with $10 \mathrm{mg} / \mathrm{L}$ chitosan exhibited a stimulated 30-fold increase in total fresh weight in comparison with PLB weight (0.25-0.3 g) at the start of the experiment. Moreover, VW with 20 and $25 \mathrm{mg} / \mathrm{L}$ chitosan did not significantly increase mean fresh weight when compared with the chitosan free control. NDM with $25 \mathrm{mg} / \mathrm{L}$ chitosan and control cultures showed a non-stimulated increase in weight of 4-5-fold. In general, liquid VW alone or when supplemented with chitosan was more effective in enhancing the growth of PLBs when compared with liquid NDM (Fig. 2b).
Assessment of genetic stability using ISSR analysis

Optimization of ISSR protocol and selection of the primers exhibited that the ISSR bands were reproducible. Of the 10 random ISSR primers used for initial screening, only 8 primers gave more than four clear and scorable bands (Tab. 1). The genetic stability was assayed for PLBs obtained from each subculture stage in both media supplemented with $10 \mathrm{mg} / \mathrm{L}$ chitosan (optimal concentration). ISSR molecular technique generated 55 band classes and the number of bands for each primer varied from 5 to 11 , with an average of 6.9 bands per ISSR primer. A total of 275 bands were generated by ISSR techniques, giving rise to monomorphic patterns across mother plant and secondary PLBs produced during the process of sub-culturing. Fig. 3 represents the monomorphic band classes generated by ISSR across mother plant and the PLBs achieved by the subculture stages of optimum chitosan $(10 \mathrm{mg} / \mathrm{L})$ in VW and NDM. Ultimately, the monomorphic banding model indicated that addition of $10 \mathrm{mg} / \mathrm{L}$ of chitosan in both media did not induce any detectable somaclonal variation.

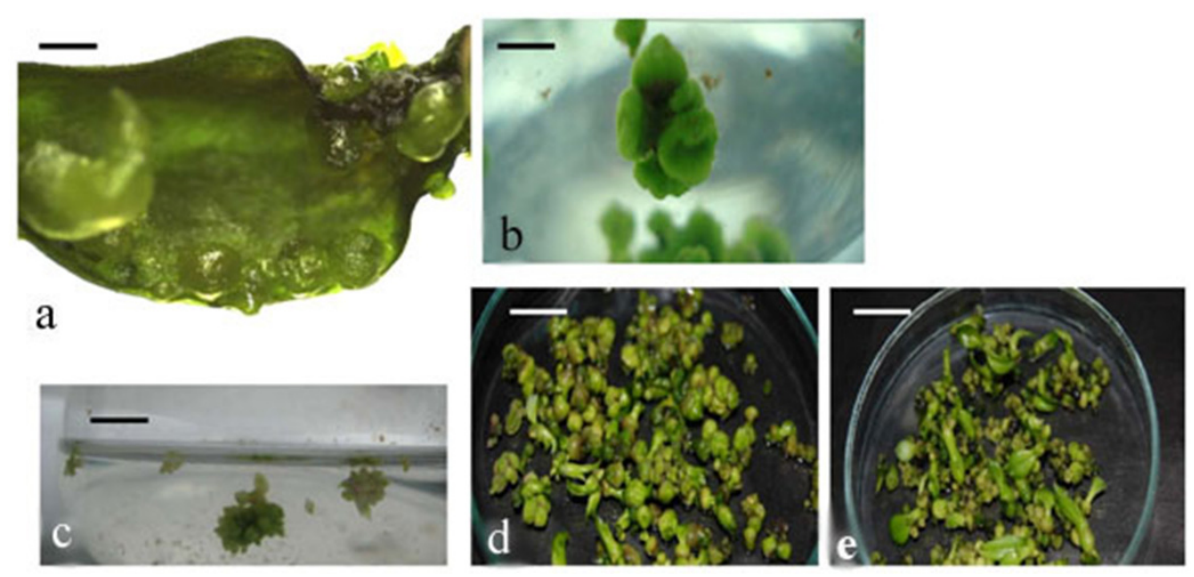

Fig. 1. In vitro micropropagation of Phalaenopsis gigantea PLBs. (a) PLB Induction from leaf segment cultured after 4 weeks of cultivation (bar $=2 \mathrm{~mm}$ ); (b) Swollen protocorm after 2 weeks of culturing (bar $=4 \mathrm{~mm}$ ); (c) Secondary PLB formation after 4 weeks in liquid culture (bar $=20 \mathrm{~mm}$ ); (d) PLB multiplication in liquid VW at $10 \mathrm{mg} / \mathrm{L}$ chitosan after 8 weeks of culturing $(\mathrm{bar}=20 \mathrm{~mm})$; (e) Leaf formation after 8 weeks of culture $($ bar $=20 \mathrm{~mm}$ )
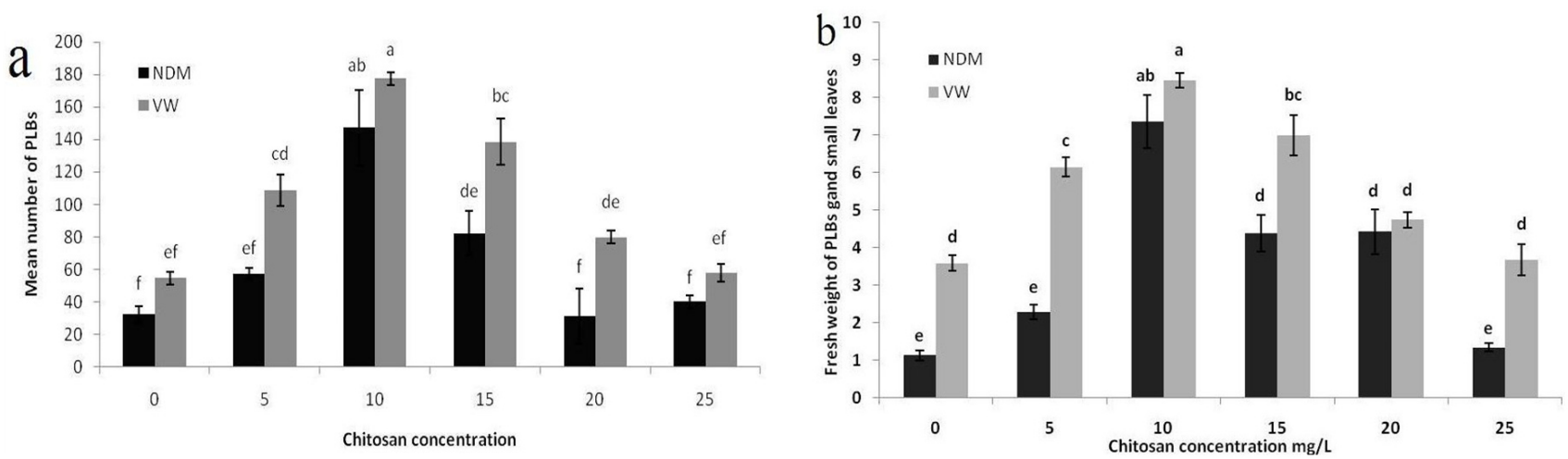

Fig. 2. (a) Effect of media types and chitosan concentrations $(\mathrm{mg} / \mathrm{L})$ on mean number of PLBs obtained after eight weeks of cultivation (b) Effect of media types and chitosan concentrations $(\mathrm{mg} / \mathrm{L})$ on total fresh weight of PLB's after eight weeks of cultivation [Standard Error was calculated from five independent experiments by one way ANOVA. Bars with different letters differ significantly $(p \leq 0.05)]$ 


\section{Discussion}

Effects of different chitosan concentrations and media types on PLBs proliferation

There have been only a few reports on in vitro effects of different chitosan types, molecular weights, deacetylation degree, polymerisation and concentration on orchid propagation (Nge et al., 2006; Pornpienpakdee et al., 2010). Various comparative analyses of plant responses to different chitosan concentrations have shown that the presence of chitosan in tissue culture medium induced higher frequencies of PLB formation and multiplication in different orchid species such as Dendrobium phalaenopsis (Nge et al., 2006), Dendrobium 'Eiskul (Pornpienpakdee et al., 2010) and Grammatophyllum speciosum (Sopalun et al., 2010). The study presented here is in conformity with other reports indicating that optimal PLB proliferation response was observed at $5-15 \mathrm{mg} / \mathrm{L}$ of chitosan range (Nge et al., 2006; Sopalun et al., 2010). Pornpienpakdee et al. (2010) observed that in VW medium supplemented with $10 \mathrm{mg} / \mathrm{L}$ polymeric chitosan of 70\% (p-70) degree of decetylation, the average number of PLBs (541) was almost 2 -fold higher than the number of PLBs (278) produced by chitosan free medium after 3 months of cultivation. PLB proliferation of Grammatophyllum speciosum, in 1/2MS liquid medium supplemented with $15 \mathrm{mg} / \mathrm{L}$ chitosan led to a 7 -fold increase in PLB growth (Sopalun et al., 2010). Similarly, in the case of Dendrobium phalaenopsis the addition of $15 \mathrm{mg} / \mathrm{L}$ chitosan in liquid VW medium was optimal for PLB multiplication (Nge et al., 2006).

According to the above observations and the findings of the present study, the effectiveness of chitosan depended on molecular weight, frequency of application, the concentration, the ratio of sugar carbons to glucosamine and $\mathrm{N}$-acetyl-glucosamine (Uthairatanakij et al., 2007). However, the PLB proliferation response to different chitosan concentrations seems to be variable from species to species. Regardless of the similar effects of $10 \mathrm{mg} / \mathrm{L}$ chitosan in both media on the mean number of secondary PLBs, the comparative analysis showed that the interaction of liquid VW and chitosan was more efficient for PLB proliferation in comparison with NDM supplemented with chitosan. Various media have been used for mass proliferation of orchid PLBs. Some reports showed that VW medium was more effective for Phalaenopsis and Dendrobium PLB proliferation (Baker et al., 1987; Kalpona et al., 2000). Ishii et al. (1998) also reported that VW with the addition of $20 \%$ CW was suitable for PLB multiplication in Phalaenopsis.

\section{Effects of chitosan on leaf organogenesis}

It has been previously reported that the presence of $20 \% \mathrm{CW}$ in tissue culture media were effective for PLBs growth and plantlet regeneration (Ng and Saleh, 2010). This natural compound is rich in cytokinins that are mostly used for PLB multiplication in the plant tissue culture
M MP S1 S2 S3 S4
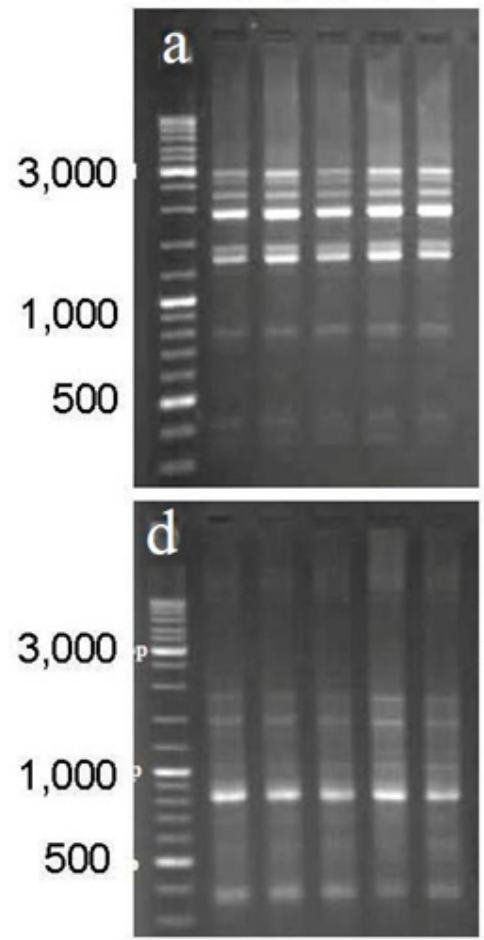

M MP S1 S2 S3 S4
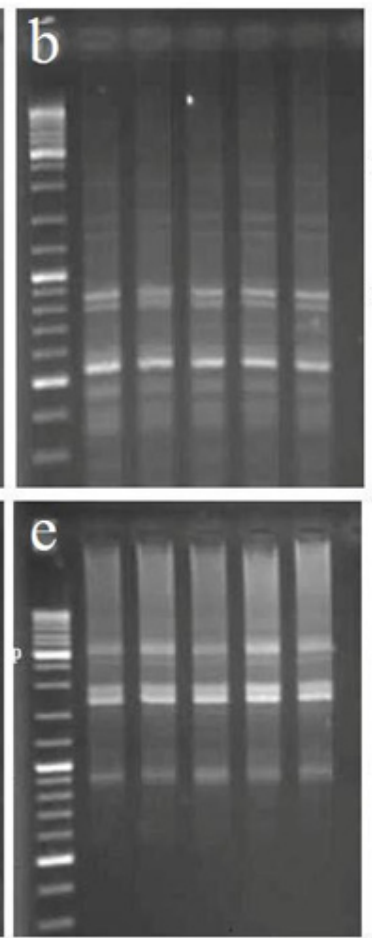

\section{MP S1 S2 S3 S4}
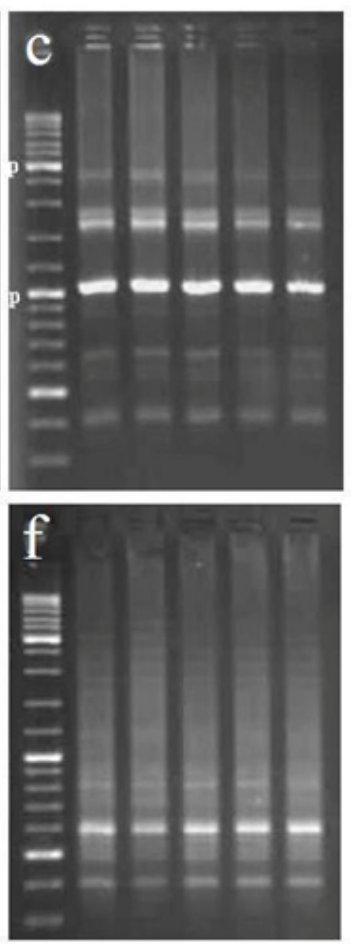

Fig. 3. ISSR banding pattern in multiplied PLBs and mother plants (lane MP is mother plant, lanes 1-4 are multiplied PLBs obtained after subcultures 1-4 with optimal chitosan). (A, B and C), Genetic stability of PLBs obtained in VW at $10 \mathrm{mg} / \mathrm{L}$ chitosan. (D, E and F), Genetic stability of PLBs in NDM at $10 \mathrm{mg} / \mathrm{L}$ chitosan 
182

industry (Huan et al., 2004). However, the synthesis of cytokinins cannot completely substitute the effect of $\mathrm{CW}$ because other phytohormones such as auxins, gibberellins and undefined chemical components in CW may exert synergistic effects with cytokinin (Yong et al., 2009). After the formation of secondary PLBs and at the time of organogenesis, the endogenous PGR synthesis system may be activated and the increased levels of endogenous PGRs in PLBs may affect differentiation of the cells in the absence of exogenous PGRs (Smith and Krikorian, 1990). Nge et al. (2006) reported the formation of juvenile leaves during multiplication of Dendrobium phalaenopsis PLBs, in liquid tissue culture medium supplemented with chitosan and the initial PLB's from meristematic buds were treated with different chitosan concentrations. The optimum fresh weight of PLB's was reported at $15 \mathrm{ppm}$ oligomer chitosan during the first three weeks of culturing. The excised meristem tissue initially increased in size and was converted into small round bodies, and the juvenile leaves appeared after five weeks of culturing. It has been previously indicated that in $D$. formosum, the effect of chitosan on growth and leaf induction depended on the growth medium composition (Limpanavech et al., 2003). The results of the present study showed that the liquid NDM supplemented with chitosan was more effective for leaf regeneration. Chitosan seems to be an appropriate growth stimulator for orchid micropropagation which may play a role in increasing the growth and development of explants by some signaling pathway similar to auxin biosynthesis via a tryptophan-independent pathway (Uthairatanakij $e t$ al., 2007).

\section{Assessment of genetic stability using ISSR analysis}

Most orchid researchers prefer to use PGR-free media to obtain genetically stable PLBs (Huan et al., 2004). As the propagation process does not involve constant exposure to exogenous PGRs, secondary PLBs with the lowest chance of somaclonal variation can be obtained. During in vitro culture of plants, variations can happen due to different reasons such as modifications in DNA methylation, gene amplification, chromosomal abnormality and point mutation (Saker et al., 2000). The use of synthetic plant growth regulators in growth media even at suboptimal concentrations was also found to induce somaclonal variations in some tissue cultured plants (Martins et al., 2004). The presence of $\mathrm{CW}$ in tissue culture media results in considerable plant cell multiplication without enhancing the number of undesirable mutations (Arditti, 2008). Pornpienpakdee et al. (2010) also reported that the addition of 10 and $20 \mathrm{mg} / \mathrm{L}$ chitosan in liquid media did not induce any somaclonal variation. Molecular analysis is being commonly used for monitoring genetic fidelity of in vitro raised plants. DNA based markers provide an effective procedure to determine tissue culture induced variations since these markers are not influenced by environmental factors (Peredo et al., 2009). PCR-based techniques such as SSR, ISSR, RAPD and AFLP have been used for as- sessment of somaclonal variation and genetic fidelity of regenerants. Different studies have shown the genetic stability of in vitro raised plants such as gerbera regenerated from tissue culture of capitulum, leaf and shoot tips (Bhatia et al., 2009), the plantlets generated from in vitro cultured banana regenerated from rhizomes (Lakshmanan et al., 2007), almond plantlets regenerated from axillary branches (Martins et al., 2004), a monopodial orchid hybrid with several shoots initiated from seedlings (Kishor and Devi, 2009) and Cymbopogon flexuosus initiated from somatic embryogenesis (rhizomatous explants) (Bhattacharya et al., 2008). The proliferation system reported here is efficient and capable of producing large numbers of genetically uniform Phalaenopsis gigantea PLBs within a relatively short period of time. The PLBs obtained using this procedure could be proliferated further in a largescale bioreactor system.

\section{Conclusions}

In summary, the present report expresses the establishment of a promising in vitro culture system to stimulate PLBs proliferation without causing a somaclonal variation rate. VW medium supplemented with $10 \mathrm{mg} / \mathrm{L}$ chitosan was most ideal for multiplication of phalaenopsis gigantea PLB. The results of study showed that leaf formation from secondary PLBs in liquid culture supplemented with chitosan largely depends on medium composition. The present protocol of PLB multiplication, as outlined in this paper will be efficient means for commercial proliferation of phalaenopsis gigantea within a relatively short period of time (8 weeks).

\section{Acknowledgement}

The first author is grateful to Sang Mi Eum, Ph.D. candidate from Department of Life Science, Ewha Womans University, Seoul, Korea that generously shared her experiences and time in assisting this research.

\section{References}

Araditti J, Ernest R (1993). Micropropagation of Orchid Wiley Publisher, New York JohnWiley and Son, $682 \mathrm{p}$.

Arditti J (2008). Micropropagation of Orchids. 2nd ed Blackwell Cambridge.

Baker KM, Mathes ML, Wallace BJ (1987). Germination of Panthieva and Cattleya seeds and development of Phalaenopsis protocorms. Lindleyana 2(2):77-83.

Bhatia R, Singh KP, Jhang T, Sharma TR (2009). Assessment of clonal fidelity of micropropagated gerbera plants by ISSR markers. Scientia Horticulturae 119(2):208-211.

Bhattacharya S, Dey T, Bandopadhyay TK, Ghosh PD (2008). Genetic polymorphism analysis of somatic embryo-derived plantlets of Cymbopogon flexuosus through RAPD assay. Plant Biotechnol Rep 2:245-252.

Chugh S, Guha S, Rao IU (2009). Micropropagation of orchids: A review on the potential of different explants. Scien- 
tia Horticulturae 122(4):507-520.

Devarumath RM, Nandy S, Rani V, Marimuthu S, Muraleedharan N, Raina SN (2002). RAPD, ISSR and RFLP fingerprints as useful markers to evaluate genetic integrity of micropropagated plants of three diploid and triploid elite tea clones representing Camellia sinensis (China type) and C. assamica ssp. Assamica (Assam-India type). Plant Cell Reports 21:166-173.

Devlieghere F, Vermeulen A, Debevere J (2004). Chitosan: antimicrobial activity, interactions with food components and applicability as a coating on fruit and vegetables. Food Microbiol 26(6):703-714.

Doyle JJ, Doyle JL (1990). Isolation of plant DNA from fresh tissue. Focus 12:13-15.

Huan LVT, Takamura T, Tanaka M (2004). Callus formation and plant regeneration from callus through somatic embryo structures in Cymbidium orchid. Plant Sci 166:1443-1449.

Ishii Y, Takamura T, Goi M, Tanaka M (1998). Callus induction and somatic embryogenesis of Phalaenopsis. Plant Cell Report 17:446-450.

Joshi P, Dhawan V (2007). Assessment of genetic fidelity of micropropagated Swertia chirayita plantlets by ISSR marker assay. Biol Plantarum 51:22-26.

Kalpona S, Sathyanarayana BN, Sachdev K (2000). Effect of coconut water and banana pulp on in vitro culture of Dendrobium. J Plant Biol 29(2):209-210.

Kishor R, Devi H (2009). Induction of multiple shoots in a monopodial orchid hybrid (Aerides vandarum Reichb. $\mathrm{f} \times$ Vanda stangeana Reichb. f) using thidiazuron and analysis of their genetic stability. Plant Cell, Tissue and Organ Culture 97:(2)121-129.

Lakshmanan V, Sreedhar RV, Bhagyalakshmi N (2007). Molecular analysis of genetic stability in long term micropropagated shoots of banana using RAPD and ISSR markers. Electron J Biotechnol 10:1-8.

Limpanavech P, Pichyangkura R, Khunwasi C, Chadchawan S, Lotrakul P, Bunjongrat P, Chaidee A, Akaraeakpanya $T$ (2003). The effects of polymer type, concentration and $\% \mathrm{DD}$ of bicatalyte modigied chitosan on flora production of Dendrobium 'Eiskul', 60-64 p. In: National chitin-chitosan conference July 17-18, 2003, Chulalongkorn University Bangkok Thailand.

Martins M, Sarmento D, Oliveira MM (2004). Genetic stability of micropropagated almond plantlets as assessed by RAPD and ISSR markers. Plant Cell Rep 23:492-496.

Nayak NR, Rath SP, Patnaik S (1997). In vitro propagation of three epiphytic orchids, Cymbidium aloifolium (L.) Sw., Dendrobium aphyllum (Roxb.) Fisch. and Dendrobium moschatum (Buch-Ham) Sw. through thidiazuroninduced high frequency shoot proliferation. Scientia Hort 243-250.

$\mathrm{Ng}$ C-Y, Saleh N (2010). In vitro propagation of Paphiopedilum orchid through formation of protocorm-like bodies. Plant Cell, Tissue and Organ Culture 105(2):193-202.

Nge KL, Nwe N, Chandrkrachang S, Stevens WF (2006). Chitosan as a growth stimulator in orchid tissue culture. Plant
Science 170(6):1185-1190.

Niknejad A, Kadir MA, Kadzimin SB (2011). In vitro plant regenreation from protocorms-like bodies (PLBs) and callus of Phalaenopsis gigantea (Epidendroideae: Orchidaceae) African Journal of Biotechnology 10(56):11808-11816.

Peredo EL, Arroyo-Garcia R, Revilla MA (2009). Epigenetic changes detected in micropropagated hop plants. J Plant Physiol 166(10):1101-1111.

Pornpienpakdee P, Singhasurasak R, Chaiyasap P, Pichyangkura R, Bunjongrat R, Chadchawan S, Limpanavech P (2010). Improving the micropropagation efficiency of hybrid Dendrobium orchids with chitosan. Scientia Horticulturae 124(4):490-499.

Rodrigues K, Kumar S (2009). Isolation and characterization of microsatellite loci in Phalaenopsis gigantea. Conservation Genetics 10(3):559-562.

Roy J, Banerjee M (2003). Induction of callus and plant regeneration from shoot-tip explants of Dendrobium fimbriatum Lindl. var. oculatum Hk. f. Sci Hortic 97:333-340.

Saiprasad GVS, Anand L, Ravishankar KV, Mythili JB, Nagesh $\mathrm{M}$, Joshi R (2004). Isolation and characterization of mRNAs differentially expressed during ripening of mango fruits. Indian Journal of Biotechnology 3:533-537.

Saker MM, Bekheer SA, Taha HS, Fahmy AS, Moursy HA (2000). Detection of somaclonal variations in tissue cultured-derived date palm plants using iso-enzyme analysis and RAPD fingerprints. Biol Plantarum 43:347-351.

Sandal I, Bhattacharya A, Ahuja PS (2001). An efficient liquid culture system for tea shoot proliferation. Plant Cell Tissue and Organ Culture 65:75-80.

Shu-guo F (2008). Tissue culture system of Phalaenopsis in genetic transformation. Journal of Biotechnology 136:164165.

Smith DL, Krikorian AD (1990). Low external pH replaces 2,4$\mathrm{D}$ in maintaining and multiplying 2,4-D initiated embryogenic cells of carrot. Plant Physiol 72:329-336.

Sopalun K, Thammasiri K, Ishikawa K (2010). Micropropagation of the Thai orchid Grammatophyllum speciosum blume. Plant Cell, Tissue and Organ Culture 101(2):143-150.

Tokuhara K, Mii M (1993). Micropropagation of Phalaenopsis and Doritaenopsis by culturing shoot tips of flower stalk buds. Plant Cell Rep 13:7-11.

Tokuhara K, Mii M (1998). Somaclonal variation in flower and inflorescence axis in micropropagated plants through flower stalk bud culture of Phalaenopsis and Doritaenopsis. Plant Biotechnol 15:23-28.

Uthairatanakij A, Teixeira da Silva JA, Obi Wan K (2007). Chitosan for improving orchid production and quality. Orchid Sci Biotechnol 1:1-5.

Vacin EF, Went FW (1949). Some pH changes in nutrient solutions. Bot Gaz 110:605-613

Yong JW, Ge L, Ng YF, Tan SN (2009). The Chemical Composition and Biological Properties of Coconut (Cocos nucifera L.) water. Molecules 14(12):5144-5164. 